\title{
Bilayers Polypyrrole Coatings for Corrosion Protection of SAE 4140 Steel
}

\author{
I.L. Lehr, S.B. Saidman* \\ Instituto de Ingeniería Electroquímica y Corrosión (INIEC), Dept. de Ingeniería \\ Química, Universidad Nacional del Sur, Av. Alem 1253, 8000 Bahía Blanca, Argentina
}

Received 16 July 2014; accepted 25 August 2014

\begin{abstract}
In this study polypyrrole (PPy) bilayers films were electrodeposited onto SAE 4140 steel. The inner layer was electropolymerized in the presence of molibdate and nitrate and the outer layer in a solution containing sodium bis (2-ethylhexyl) sulfosuccinate (AOT). The electrosynthesis was done under potentiostatic conditions. The corrosion protection properties of the films were examined in sodium chloride solution by open circuit measurements, linear polarization and electrochemical impedance spectroscopy (EIS). The bilayer coatings present an improved anticorrosive performance with respect to single PPy films.
\end{abstract}

Keywords: Polypyrrole; Bilayers; Molybdate; AOT; Anticorrosive properties; SAE 4140 steel.

\section{Introduction}

It has been demonstrated that the use of conducting polymers can provide corrosion protection for metallic substrates. Several studies have reported that the electrodeposition of polypyrrole (PPy) films on pure iron [1,2], mild steel [3-5] or stainless steel [6] can effectively inhibit the corrosion of these materials. On the other hand several works have investigated the performance of PPy bilayer coatings electrosynthesized on mild or carbon steel. It has been reported, for example, the electrosynthesis of an inner layer constituted by PPy films doped with phosphomolybdate ions which stabilize the passive oxide film [7,8]. The outer PPy film was doped with anions such as naphthalenedisulfonate dihydroxynaphthalenedisulfonate, anthraquinonedisulfonate or dodecylsulfate [7, 8]. The top layer impedes the ingress of chloride ions, and thus, the bilayers

\footnotetext{
* Corresponding author. E-mail address: ssaidman@criba.edu.ar
} 
provide better protection than a single PPy coating. Deslouis et al. have also informed that PPy bilayers electroformed films in presence of potassium tetraoxalate (inner film) and sodium dodecyl sulfate (outer film) can keep the iron passive for a long time without showing signs of corrosion [9]. On the other hand, the electrodeposition of other polymers such as polyaniline $[10,11]$ or polyphenol [12] onto steel electrodes previously coated with PPy can improve the anticorrosive properties with respect to a single film.

In previous works, we showed that the AOT as dopant agent plays a dual role of dopant and surfactant in the electropolymerization process [13-15]. The presence of this surfactant in the electrodeposition solution improved the efficiency of the process and the characteristics of the conducting polymers. Moreover, some studies have informed that the polymer formed in alkaline solution of molybdate and nitrate has good inhibition efficiency on the corrosion of 316L stainless steel in $0.15 \mathrm{M} \mathrm{NaCl}$ solution [16]. This protection is associated with a combination of factors such as the corrosion inhibition character of molybdate and nitrate, the fixed negative charge of molybdate in the polymer, the galvanic interaction between the polymer and the steel and the greater stability of the oxide formed at $\mathrm{pH} 12$.

In this paper we present results on the electrodeposition of PPy bilayers onto SAE 4140 steel. The objective was to combine the properties of single PPy films in a unique coating. In this regard, PPy film was electrosynthesized in the presence of molybdate and nitrate as inner layer and the outer film was formed by PPy doped with AOT. The influence of different parameters on the anticorrosive performance of PPy bilayers was analized. The characterization of the films was done using electrochemical techniques and SEM/EDX. For comparative purposes, the anticorrosive behavior was also checked for single PPy films and uncoated SAE 4140 steel.

\section{Experimental}

\section{Chemicals and materials}

All chemicals were reagent grade and solutions were made in twice distilled water. Pyrrole was purchased from Across Organics and it was freshly distilled under reduced pressure before use. In order to avoid the slow hydrolysis of AOT all the measurements were done with freshly prepared samples.

SAE 4140 steel rods embedded in a Teflon holder with an exposed area of 0.070 $\mathrm{cm}^{2}$ were used as working electrodes. Before each experiment, the exposed surfaces were polished to a 1000 grit finish using $\mathrm{SiC}$, then degreased with acetone and washed with triply distilled water. All the potentials were measured against a saturated calomel electrode (SCE) and a platinum sheet was used as a counter electrode.

\section{Instrumentation}

The cell was a $20 \mathrm{~cm}^{3}$ Metrohm measuring cell. Electrochemical measurements were done using a potentiostat-galvanostat PAR 273A and VoltaLab40 
Potentiostat PGZ301. The frequency used for the impedance measurements was changed from $100 \mathrm{kHz}$ to $10 \mathrm{mHz}$, and the signal amplitude was $10 \mathrm{mV}$.

A dual stage ISI DS 130 SEM and an EDAX 9600 quantitative energy dispersive X-ray analyzer were used to examine the electrode surface characteristics. Wavelength dispersive X-ray spectroscopy (WDS) was performed using a JEOL 8900 Electron Probe Microanalyzer to verify the successful incorporation of molybdenum and sulfur into the films.

The elemental analysis was carried out with an atomic emission spectrometer with inductively coupled plasma (ICP-AES), Shimadzu's simultaneous ECPE9000, according to the EPA 200.7 method.

Electrical conductivity was measured by Two-Probe Method using a homemade device and film adhesion was tested measuring the force necessary to peeloff the film using a Scotch ${ }^{\circledR}$ MagicTM double coated Tape 810 (3M) and a Mecmesin basic force gauge (BFG $50 \mathrm{~N})$.

\section{Electrosynthesis and characterization of coatings}

Electropolymerization of the bilayers was performed as follows:

- BiPPy-pH 8 coatings

The inner layer was electrodeposited onto SAE 4140 steel at $0.9 \mathrm{~V}$ for $600 \mathrm{~s}$ in a solution containing $0.70 \mathrm{M} \mathrm{MoO}_{4}{ }^{2-}, 0.25 \mathrm{M} \mathrm{NO}_{3}{ }^{-}$and $0.50 \mathrm{M} \mathrm{Py}, \mathrm{pH} 8$, and the outer layer was electroformed at $1 \mathrm{~V}$ during $1200 \mathrm{~s}$ in a solution containing 0.05 $\mathrm{M}$ AOT and $0.1 \mathrm{M}$ Py, pH 6.

- BiPPy-pH 8 coatings

The inner layer was electrodeposited onto SAE 4140 steel at $0.9 \mathrm{~V}$ for $400 \mathrm{~s}$ in a solution containing $0.70 \mathrm{M} \mathrm{MoO}_{4}{ }^{2-}, 0.25 \mathrm{M} \mathrm{NO}_{3}{ }^{-}$and $0.50 \mathrm{M} \mathrm{Py}, \mathrm{pH} 12$, and the outer layer was electroformed at $1 \mathrm{~V}$ during $260 \mathrm{~s}$ in a solution containing 0.05 M AOT and 0.1 M Py, pH 6.

- Inverted bilayer coating

PPy bilayers were deposited with an inverted order of single PPy films. The inner layer was electrodeposited onto SAE 4140 steel at $1 \mathrm{~V}$ during $1200 \mathrm{~s}$ in a solution containing $0.05 \mathrm{M} \mathrm{AOT}$ and $0.1 \mathrm{M} \mathrm{Py}, \mathrm{pH} \mathrm{6}$, and the outer layer was electroformed at $0.9 \mathrm{~V}$ for $600 \mathrm{~s}$ in a solution containing $0.70 \mathrm{M} \mathrm{MoO}_{4}{ }^{2-}, 0.25 \mathrm{M}$ $\mathrm{NO}_{3}{ }^{-}$and $0.50 \mathrm{M} \mathrm{Py}, \mathrm{pH} 8$.

PPy single films were electrodeposited onto SAE 4140 steel by employing the same electrodeposition charge that corresponded to the bilayers, in order to compare the anticorrosion performance of the different coatings:

- $\mathrm{PPy}-\mathrm{MoO}_{4}{ }^{2-} \mathrm{NO}_{3}{ }^{-} \mathrm{pH} 8$ coating

The film was electrosynthesized at $0.9 \mathrm{~V}$ for $1500 \mathrm{~s}$ in a solution containing 0.70 $\mathrm{M} \mathrm{MoO}_{4}{ }^{2-}, 0.25 \mathrm{M} \mathrm{NO}_{3}{ }^{-}$and $0.50 \mathrm{M} \mathrm{Py}, \mathrm{pH} 8$.

- $\mathrm{PPy}-\mathrm{MoO}_{4}{ }^{2-} \mathrm{NO}_{3}{ }^{-} \mathrm{pH} 12$ coating

The film was electropolymerized at $0.9 \mathrm{~V}$ for $1500 \mathrm{~s}$ in a solution containing 0.70 $\mathrm{M} \mathrm{MoO}_{4}{ }^{2-}, 0.25 \mathrm{M} \mathrm{NO}_{3}{ }^{-}$and $0.50 \mathrm{M} \mathrm{Py}, \mathrm{pH} 12$

- PPy-AOT coating

The film was electrodeposited at $1 \mathrm{~V}$ during $1800 \mathrm{~s}$ in a solution containing 0.05 M AOT and $0.1 \mathrm{M} \mathrm{Py,} \mathrm{pH} 6$. 
The corrosion performance was investigated in $0.5 \mathrm{M} \mathrm{NaCl}$ solution by a potentiodynamic method, by the variation of the open circuit potential (OCP) as a function of time and by electrochemical impedance spectroscopy (EIS). The electrodes were allowed to equilibrate at the fixed voltage before the ac measurements.

The Tafel tests were carried out by polarizing from cathodic to anodic potentials with respect to the open circuit potential at $0.001 \mathrm{Vs}^{-1}$ in an aerated $0.5 \mathrm{M} \mathrm{NaCl}$ solution. Estimation of corrosion parameters was realized by the Tafel extrapolation method. The extrapolation of anodic and/or cathodic lines for charge transfer controlled reactions gives the corrosion current density $\left(i_{\text {corr }}\right)$ at the corrosion potential $\left(\mathrm{E}_{\mathrm{corr}}\right)$. All experiments were conducted after the steadystate $\mathrm{E}_{\text {corr }}$ was attained, which normally took $1 \mathrm{~h}$ after immersion in the solution. Each set of experiments was repeated two to four times to ensure reproducibility.

\section{Results and discussion}

\section{Electrodeposition of PPy bilayers}

Uniform and adherent PPy bilayers were obtained by a potentiostatic method. The inner layer was electrodeposited onto SAE 4140 steel at $0.9 \mathrm{~V}$ for $600 \mathrm{~s}$ in a solution containing $0.70 \mathrm{M} \mathrm{MoO}_{4}{ }^{2-}, 0.25 \mathrm{M} \mathrm{NO}_{3}{ }^{-}$and $0.50 \mathrm{M}$ Py at pH 8 (Fig. $1 \mathrm{~A}$, curve a). Initially, the magnitude of the current decreases, which is associated with oxide growth and, after this stage, the formation of the polymer starts. The coated electrode was rinsed with tridistilled water before being immersed in the electrochemical cell for the electrodeposition of the second film of PPy. This outer layer was electroformed at $1 \mathrm{~V}$ during $1200 \mathrm{~s}$ in a solution containing $0.05 \mathrm{M}$ AOT and $0.1 \mathrm{M}$ Py at pH 6 (Fig. 1A, curve b). For simplicity purposes this bilayer is called BiPPy-pH8.

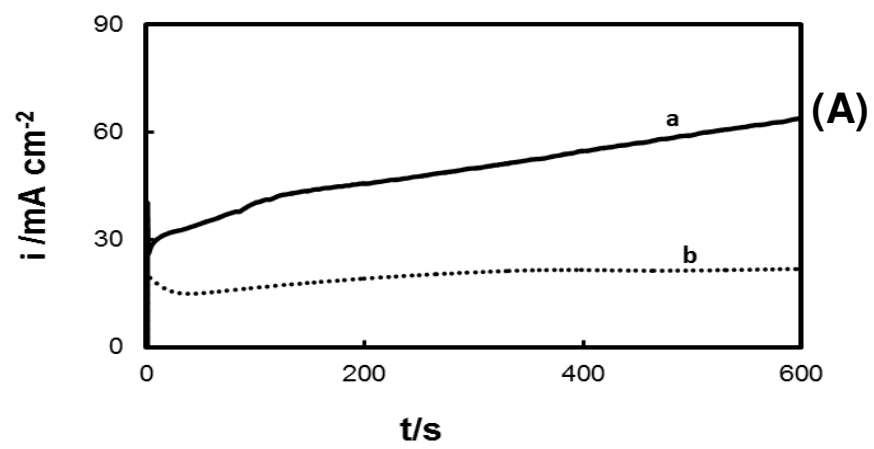

Figure 1A. Potentiostatic transients obtained for: (A) (a) a SAE 4140 steel electrode at $0.9 \mathrm{~V}$ for $600 \mathrm{~s}$ in $0.70 \mathrm{M} \mathrm{MoO}_{4}{ }^{2-}, 0.25 \mathrm{M} \mathrm{NO}_{3}{ }^{-}$and $0.50 \mathrm{M} \mathrm{Py}, \mathrm{pH} 8$ solution and (b) a SAE 4140 steel coated with PPy films at $1 \mathrm{~V}$ for $1200 \mathrm{~s}$ in $0.05 \mathrm{M}$ AOT and 0.50 M Py, pH 6 solution (BiPPy-pH8).

The charge consumed during the electrosynthesis of the outer PPy film is approximately 20 percent of the charge involved in the electroformation of the PPy coating doped with AOT onto uncoated steel, which is obviously due to the presence of the inner film. When the inner PPy film is obtained in a solution 
containing $0.70 \mathrm{M} \mathrm{MoO}_{4}{ }^{2-}, 0.25 \mathrm{M} \mathrm{NO}_{3}{ }^{-}$and $0.50 \mathrm{M}$ Py but at $\mathrm{pH} 12$, the charge involved in the electrosynthesis of the polymer is twice than that employed at $\mathrm{pH}$ 8 (Fig. 1B, curve a). For simplicity purposes this bilayer is called BiPPy-pH12. The charge involved in the formation of the outer layer is about four times higher than the one employed for the other bilayer (Fig. 1B, curve b).

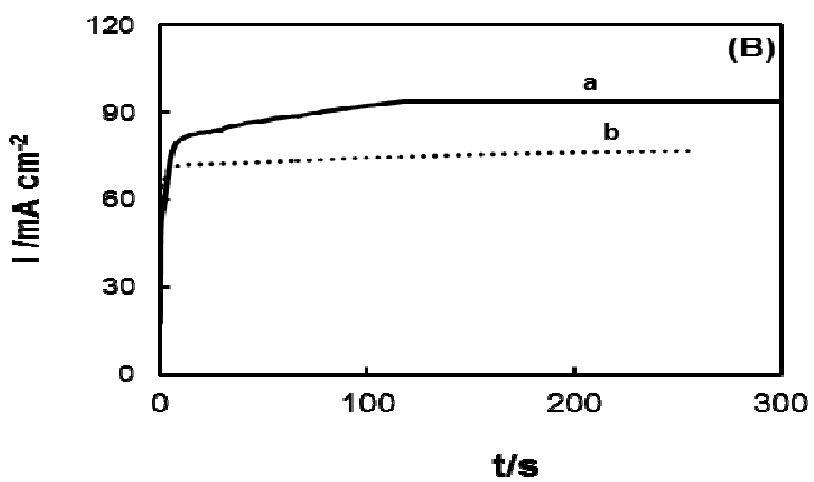

Figure 1B. Potentiostatic transients obtained for: (B) (a) a SAE 4140 steel electrode at $0.9 \mathrm{~V}$ for $400 \mathrm{~s}$ in $0.70 \mathrm{M} \mathrm{MoO}_{4}{ }^{2-}, 0.25 \mathrm{M} \mathrm{NO}_{3}{ }^{-}$and $0.50 \mathrm{M} \mathrm{Py}, \mathrm{pH} 12$ solution and (b) a SAE 4140 steel coated with PPy films at $1 \mathrm{~V}$ for $260 \mathrm{~s}$ in $0.05 \mathrm{M}$ AOT and $0.50 \mathrm{M}$ Py, pH 6 solution (BiPPy-pH12).

\section{PPy bilayers characterization}

The SEM image of the BiPPy-pH8 film shows the typical granular structure of PPy (Fig. 2). A gelatinous film in some areas was observed around the polymer. It was postulated that this gel-like material is a mixed $\mathrm{NaAOT}-\mathrm{Fe}(\mathrm{AOT})_{3}$ lamellar mesophase [17].

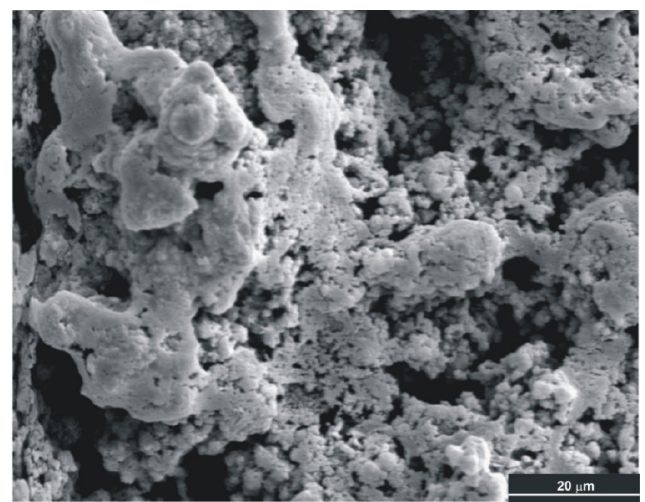

Figure 2. SEM micrograph of the BiPPy-pH8 film.

EDX analysis established the presence of sulfur and molybdenum, indicating that both AOT and molybdate are incorporated into the polymer matrix (Fig. 3).

Semi-quantitative elemental analysis showed that the amount of sulfur is nearly twice as that of molybdenum which may be associated with the depth of the analysis. This result was verified by wavelength dispersive X-ray spectroscopy (WDS) (Fig. 4). 


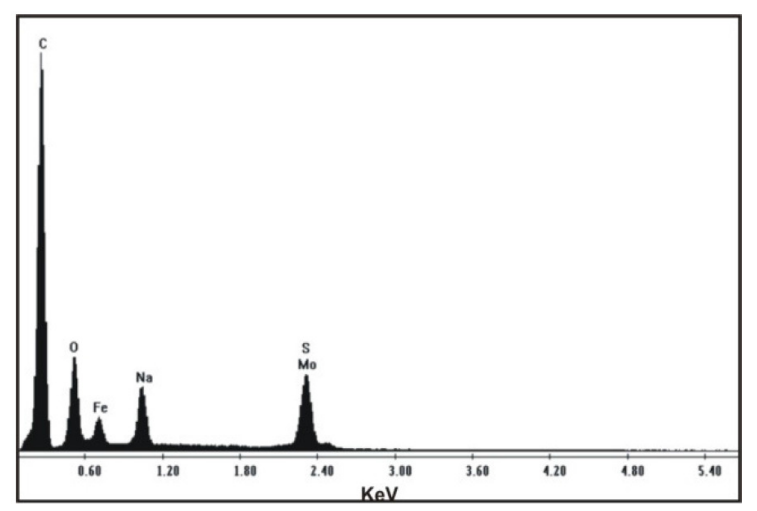

Figure 3. EDX spectrum of the BiPPy-pH8 film.

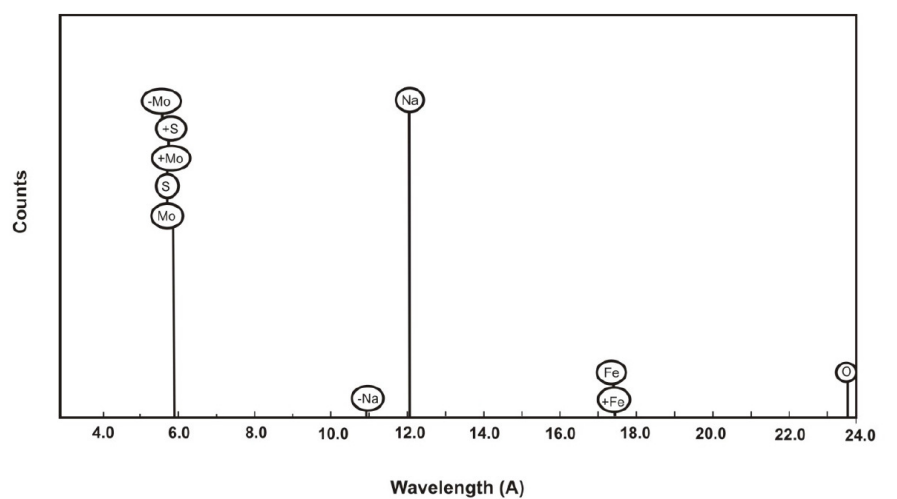

Figure 4. WDS spectrum of the BiPPy-pH8 film. The horizontal axis is the detected Xray wavelength in $\breve{A}$ and the vertical axis is counts.

The coating electrosynthesized in a $\mathrm{pH} 12$ solution (BiPPy-pH12) also shows the typical granular structure with similar grain sizes of those found for BiPPy-pH8 coating, although with a more homogeneous distribution (Fig. 5).

The adhesion force, so called pull-off force, of the different coatings is informed in Table 1 in order to compare them. The necessary force to peel-off the films had the same order of magnitude, being the BiPPy-pH8 coating the most adherent. However, all coatings could be removed only by mechanical polishing.

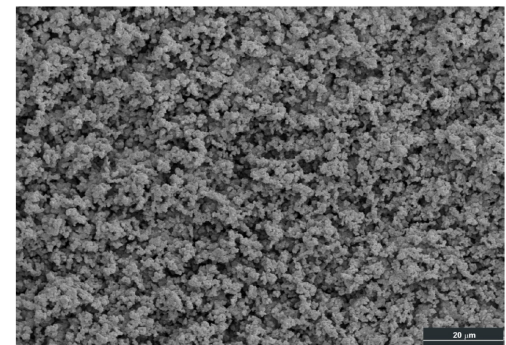

Figure 5. SEM micrograph of BiPPy-pH12 film.

\section{Anticorrosive properties of bilayers}

Fig. 6 shows the variation of the open circuit potential (OCP) as a function of time in $0.5 \mathrm{M} \mathrm{NaCl}$. Usually, this procedure is used to evaluate the degree of corrosion protection attained after covering the substrate with the conducting polymer. When the coating is not sufficiently protective the pitting potential of the uncovered electrode $(-0.56 \mathrm{~V})$ is inevitably reached (Fig. $6 \mathrm{~A}$, small insert). 
The initial OCP value for PPy BiPPy-pH8 was $0.20 \mathrm{~V}$ (Fig. $6 \mathrm{~A}$, curve a). Then, the OCP decreases until around $-0.15 \mathrm{~V}$ where it remains for approximately two weeks. After 30 days of immersion, the OCP value is approximately $-0.45 \mathrm{~V}$. This potential value was still nobler than that for the uncoated electrode. A similar response was obtained for BiPPy-pH12 although in this case the corrosion potential of the uncoated steel is reached faster (Fig. 6A, curve b).

Table 1. Adherence force obtained for different PPy coatings of coated SAE 4140 steel after peel-off testing. The coatings were electrosynthesized with the same charge (45 $\left.\mathrm{C} / \mathrm{cm}^{2}\right)$.

\begin{tabular}{|l|c|}
\hline \multicolumn{1}{|c|}{ Sample } & Adherence force (N) \\
\hline PPy-MoO $_{4}{ }^{2-}-\mathrm{pH} 12$ & 14.30 \\
\hline $\mathrm{PPy}_{\mathrm{MoO}}{ }_{4}{ }^{2-}-\mathrm{pH} 8$ & 16.40 \\
\hline PPy-AOT & 17.10 \\
\hline BiPPy-pH12 & 26.30 \\
\hline BiPPy-pH8 & 29.30 \\
\hline Inverted BiPPy & 16.90 \\
\hline
\end{tabular}

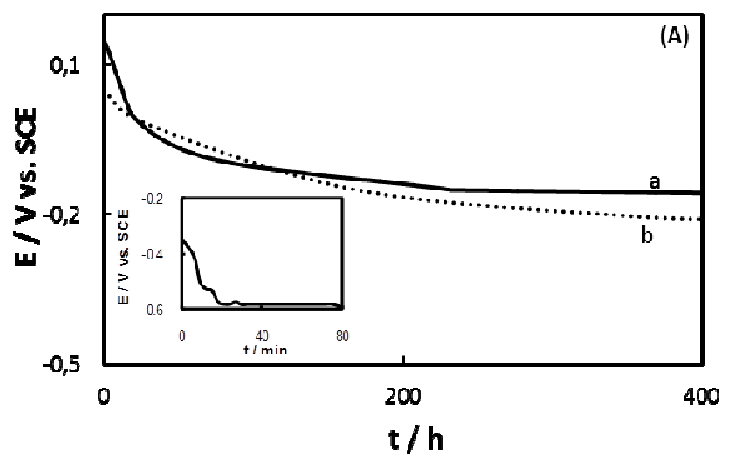

Figure 6A. Time dependence of the OCP in $0.5 \mathrm{M} \mathrm{NaCl}$ for: (A) (a) BiPPy-pH8 film (b) BiPPy-pH12 film and (c) uncoated SAE 4140 steel (small insert).

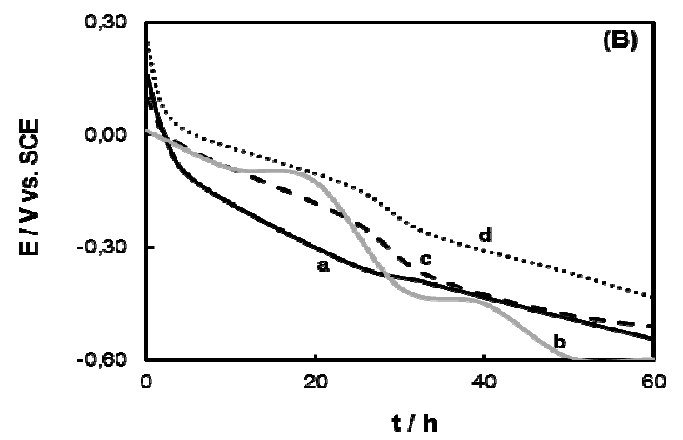

Figure 6B. Time dependence of the OCP in $0.5 \mathrm{M} \mathrm{NaCl}$ for: (B) (a) $\mathrm{PPy}_{-}-\mathrm{MoO}_{4}{ }^{2-} \mathrm{NO}_{3}{ }^{-}$ pH8 film. (b) $\mathrm{PPy}_{-} \mathrm{MoO}_{4}{ }^{2-} \mathrm{NO}_{3}{ }^{-} \mathrm{pH} 12$ film. (c) PPy-AOT film. (d) Inverted bilayer film.

For comparative purpose, the behavior of single PPy films (PPy doped with

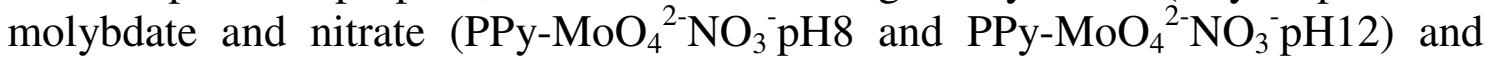
PPy doped with AOT (PPy-AOT)) are also presented (Fig. 6 B). The performance of the PPy bilayer with an inverted order of the single layers 
(inverted bilayer) is also included in the same figure. The protection time for all these coatings is shorter compared to that of the bilayers. The potential corresponding to the bare electrode is attained in these cases after about two days of immersion in the chloride solution. These results indicate that the PPy bilayer is a very efficient barrier for protecting the steel against corrosion.

In order to confirm the improvement in the corrosion protection of the steel, the Fe quantity released under OCP conditions in $0.5 \mathrm{M} \mathrm{NaCl}$ solution during 20 days of immersion was analyzed and compared (Table 2). In the case of the bare substrate the immersion time was shorter $(96 \mathrm{~h})$. The quantity of Fe released was low when the substrate was coated with the bilayer coatings, corroborating a better performance even after a long exposure time. The concentrations of Mo and $\mathrm{S}$ in solution were also analyzed. The obtained results corroborate that both anions are incorporated in the bilayers and they also indicate the bilayers provided the best protection. More particularly, the formation of PPy-AOT film on top of $\mathrm{PPy}_{-} \mathrm{MoO}_{4}{ }^{2-} \mathrm{NO}_{3}{ }^{-} \mathrm{pH} 8$ coating seems to block the pores of the inner layer and consequently prevents chloride ingress.

Table 2. Elemental analysis corresponding to a $0.5 \mathrm{M} \mathrm{NaCl}$ solution after a sample was immersed: uncoated SAE 4140 steel after 4 days of immersion; $\mathrm{PPy}-\mathrm{MoO}_{4}{ }^{2-} \mathrm{NO}_{3}{ }^{-} \mathrm{pH} 8$ coated SAE 4140 steel, PPy- $\mathrm{MoO}_{4}{ }^{2-} \mathrm{NO}_{3}{ }^{-} \mathrm{pH} 12$ coated SAE 4140 steel, PPy-AOT coated SAE 4140 steel, BiPPy-pH12 coated SAE 4140 steel, BiPPy-pH8 coated SAE 4140 steel and inverted BiPPy coated SAE 4140 steel, all coatings after 20 days of immersion.

\begin{tabular}{|c|c|c|c|}
\hline Sample / immersion time & $\mathrm{Fe}(\mathrm{mg} / \mathrm{L})$ & Mo (mg/L) & $\mathrm{S}(\mathrm{mg} / \mathrm{L})$ \\
\hline $\mathrm{PPy} \mathrm{MoO}_{4}{ }^{2-}-\mathrm{pH} 12$ / 20 days & 7.99 & 10.20 & ----------------- \\
\hline $\mathrm{PPy}-\mathrm{MoO}_{4}{ }^{2-}-\mathrm{pH} 8 / 20$ days & 3.02 & 5.10 & ---------------- \\
\hline PPy-AOT / 20 days & 1.44 & ----------------- & 2.28 \\
\hline BiPPy-pH12 / 20 days & 0.88 & 2.82 & 1.22 \\
\hline BiPPy-pH8 / 20 days & 0.75 & $<0.2$ & 0.72 \\
\hline Inverted BiPPy / 20 days & 1.60 & 0.50 & 1.63 \\
\hline Uncoated SAE 4140 steel / 4 days & 4.60 & ----------------- & ------------ \\
\hline
\end{tabular}

Tafel plots of the PPy bilayers (BiPPy-pH8 and BiPPy-pH12) and uncoated SAE 4140 steel are presented in Fig. 7. Estimation of the corrosion parameters $\left(\mathrm{E}_{\text {corr }}\right.$, cathodic $\left(\mathrm{B}_{\mathrm{c}}\right)$ and anodic $\left(\mathrm{B}_{\mathrm{a}}\right)$ Tafel slopes and corrosion current $\left.\left(\mathrm{i}_{\text {corr }}\right)\right)$ are reported in Table 3 for all coatings studied. The $i_{\text {corr }}$ values measured for the steel covered with PPy coatings are significantly lower than those of the bare steel. However, this decrease is more noticeable for the bilayers being their $\mathrm{i}_{\text {corr }}$ two and three orders of magnitude lower than that of the uncoated substrate. BiPPy-pH8 coating presents the lowest corrosion rate with respect to the other films.

The polarization curves for the SAE 4140 electrode covered by PPy bilayers and the uncoated steel in $\mathrm{NaCl}$ solution are presented in Fig. 8A. The curves for single PPy films and for the inverted bilayer are also shown (Fig. 8B). By comparing the polarization curves, it is evident that BiPPy-pH8 coating provides a significant improvement in the corrosion resistance. The corresponding curve initially exhibits low current densities (Fig. 8A, curve a), indicating that the corrosion reaction of SAE 4140 steel is retarded by the presence of the bilayer. A current peak is observed at more positive potentials. 


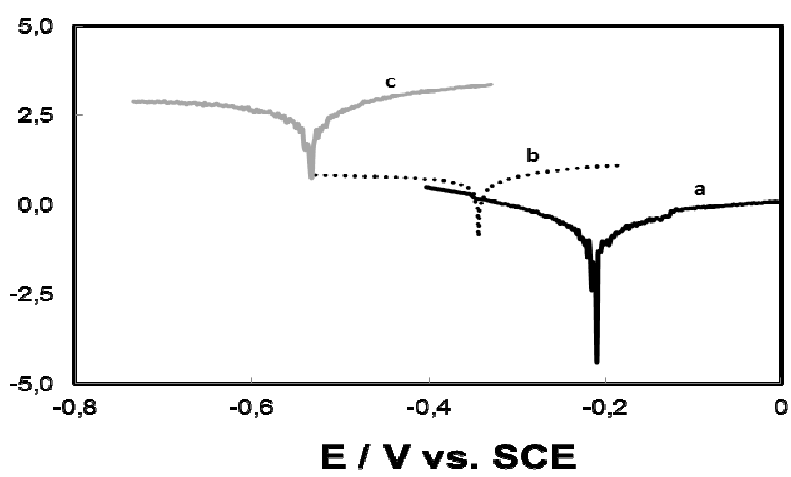

Figure 7. Tafel curves obtained in $0.5 \mathrm{M} \mathrm{NaCl}$ for: (a) BiPPy-pH8 coated SAE 4140 steel, (b) BiPPy-pH12 coated SAE 4140 steel and (c) uncoated SAE 4140 steel.

Table 3. Corrosion parameters calculated from Tafel polarization plots for uncoated steel, PPy-coated steel (PPy- $\mathrm{MoO}_{4}{ }^{2-} \mathrm{NO}_{3}{ }^{-} \mathrm{pH} 8, \mathrm{PPy}_{-} \mathrm{MoO}_{4}{ }^{2-} \mathrm{NO}_{3}{ }^{-} \mathrm{pH} 12$ and PPy-AOT) and BiPPy- coated steel (BiPPy-pH12, BiPPy-pH8 and inverted BiPPy).

\begin{tabular}{|l|c|c|c|c|}
\hline \multicolumn{1}{|c|}{ Sample } & $\begin{array}{c}\mathbf{E}_{\text {corr }} / \mathbf{V} \\
\mathbf{v s .} \text { SCE }\end{array}$ & $\begin{array}{c}\mathbf{i}_{\text {corr }} \\
\boldsymbol{\mu A} / \mathbf{c m}^{2}\end{array}$ & $\begin{array}{c}\mathbf{B}_{\mathbf{c}} / \\
\mathbf{m V} \mathbf{d e c}^{-1}\end{array}$ & $\begin{array}{c}\mathbf{B}_{\mathbf{a}} / \\
\mathbf{m V}_{\mathbf{d e c}^{-1}}\end{array}$ \\
\hline Uncoated SAE 4140 steel & $-0,531$ & 74,9 & -188 & 109 \\
\hline PPy-MoO $_{4}{ }^{2-}-\mathrm{pH} 12$ & $-0,505$ & 69,18 & -200 & 250 \\
\hline PPy-MoO $_{4}{ }^{2-}-\mathrm{pH} 8$ & $-0,437$ & 35.48 & $-357,1$ & 153,8 \\
\hline PPy-AOT & $-0,385$ & 6,3 & $-210,7$ & 268,8 \\
\hline BiPPy-pH12 & $-0,347$ & 3,98 & $-454,5$ & 125 \\
\hline BiPPy-pH8 & $-0,216$ & 0,41 & $-115,7$ & 189,6 \\
\hline inverted BiPPy & $-0,395$ & 7,08 & $-167,1$ & 116 \\
\hline
\end{tabular}

The anodic peak current increases with the thickness of the inner film, indicating that this peak is associated with the oxidation of the polymer. Moreover, the sample was subjected to $3 \mathrm{~V}$ without showing signs of corrosion. At this stage the chloride solution did not present the typical yellow coloration indicative of iron dissolution. A similar curve was obtained for the BiPPy-pH12 coating, but higher current densities with small oscillations were registered in this case (Fig. $8 \mathrm{~A}$, curve b). At the end of the potential scan, a yellow coloration denoting iron dissolution was observed.

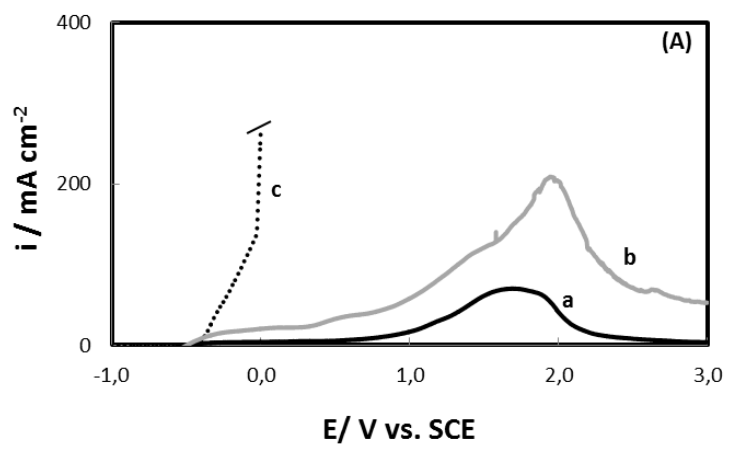

Figure 8A. The polarization behavior in $0.5 \mathrm{M} \mathrm{NaCl}$ at $0.001 \mathrm{Vs}^{-1}$ of: (A) (a) BiPPypH 8 coating, (b) BiPPy- $\mathrm{pH} 8$ coating and (c) uncoated SAE 4140 steel.

The single PPy films show current oscillations and a significant increase in the current density at potentials above $1.5 \mathrm{~V}$ denotes the onset of pitting corrosion. 
The curve obtained for the inverted bilayer exhibited current oscillations which were more noticeable at the end of the scanning. In both cases, a yellow coloration could be distinguished in the chloride solution.

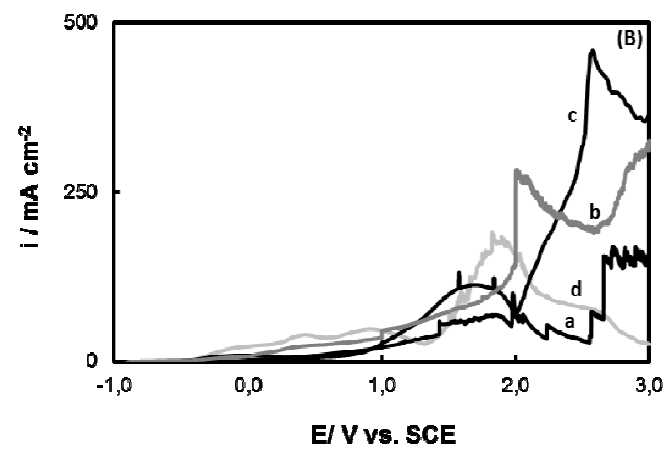

Figure 8B. The polarization behavior in $0.5 \mathrm{M} \mathrm{NaCl}$ at $0.001 \mathrm{Vs}^{-1}$ of: (B) (a) PPy$\mathrm{MoO}_{4}{ }^{2-} \mathrm{NO}_{3}{ }^{-} \mathrm{pH} 8$ film, (b) $\mathrm{PPy}_{-} \mathrm{MoO}_{4}{ }^{2-} \mathrm{NO}_{3}{ }^{-} \mathrm{pH} 12$ film and (c) PPy-AOT film. (d) Inverted bilayer film.

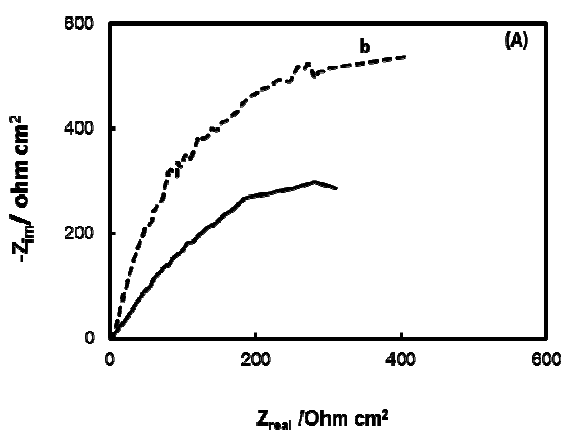

Figure 9A. Nyquist plots of the impedance spectra for the PPy bilayers at the open circuit potential in $0.5 \mathrm{M} \mathrm{NaCl}$ after different immersion times: (A) BiPPy-pH8 coating. Curves (a) and (b) correspond to 5 min and 15 days of immersion, respectively.

EIS mesurements were conducted to evaluate the anticorrosive performace of PPy coatings at different immersion times in aerated $0.5 \mathrm{M} \mathrm{NaCl}$ solution. Fig. 9 shows the Nyquist diagrams for PPy bilayers. At the beginning of immersion of BiPPy-pH8 coatings the impedance spectrum presents a large depressed semicircle indicating that the process is controlled by charge transfer reaction (Fig. 9A, curve a) while the impedance response of the BiPPy-pH12 film shows two incomplete semicircles (Fig. 9B, curve a). According to several authors, the semicircle at high frequencies can be explained by considering the charge transfer resistance against iron (substrate) dissolution in parallel with electrical double layer capacitance $[18,19]$. As exposure times increases, in both cases the responses were similar to that obtained initially but the semicircle diameter increases (Fig. 9A and 9B, curve b). At this stage the OCP values were close at $0.20 \mathrm{~V}$ although the OCP value for BiPPy-pH8 is slightly more positive. An increase in the total impedance for the BiPPy-pH8 coating compared to the BiPP$\mathrm{pH} 12$ film which also corroborates the better protective properties. 


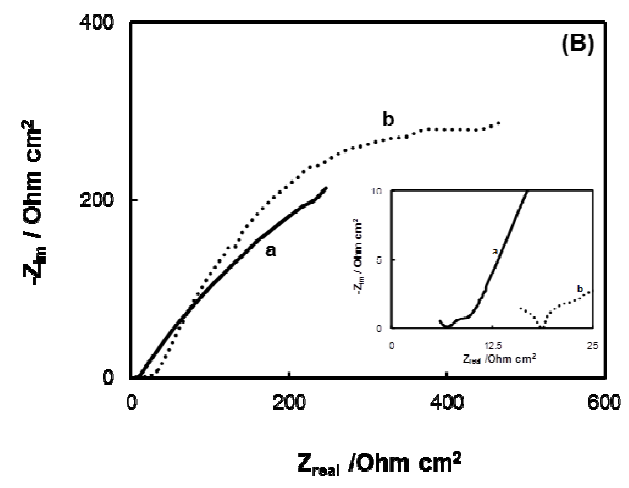

Figure 9B. Nyquist plots of the impedance spectra for the PPy bilayers at the open circuit potential in $0.5 \mathrm{M} \mathrm{NaCl}$ after different immersion times: (B) BiPPy-pH12 coating. Curves (a) and (b) correspond to $5 \mathrm{~min}$ and 15 days of immersion, respectively.

The impedance responses of the single PPy films and inverted bilayer were presented in Fig. 10. A remarkable difference in the Nyquist plots compared to the spectra obtained for the bilayer films is the decrease in the total impedance. Furthermore there is a noticeable change in the impedance spectrum shape (kinetic control type). Particularly, when the OCP values are close to the corrosion potential of uncoated steel, a diffusional impedance dominated the response for single PPy films and inverted bilayers but with different slopes magnitudes. The lineal portion can be related to diffusion of corrosive species through the pores of film [20]. These results corroborate that the top coat reduces the permeability and water mobility within the coating improving the corrosion performance significantly.

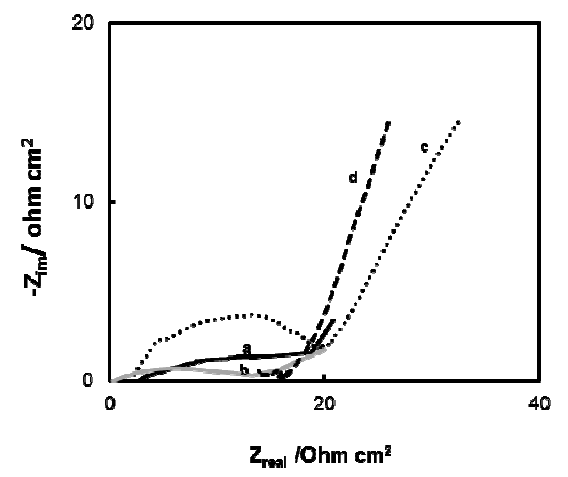

Figure 10. Nyquist plots of the impedance spectra for the PPy films at the open circuit

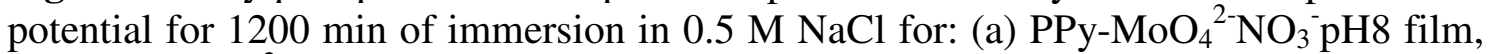
(b) $\mathrm{PPy}-\mathrm{MoO}_{4}{ }^{2-} \mathrm{NO}_{3}{ }^{-} \mathrm{pH} 12$ film, (c) PPy-AOT film and (d) inverted bilayer. All coatings were obtained by employing the same electrodeposition charge that corresponded to the bilayers $\left(45 \mathrm{C} / \mathrm{cm}^{2}\right)$.

Several studies have reported the relationship between the anticorrosive properties, the morphology and the electrical conductivity of conducting polymers [10-21,22]. It has been concluded that an open structure presents low conductivity values and that these films provide less corrosion protection. It has 
been postulated that the anticorrosive properties provided by conducting polymers are related to the galvanic interaction between the metallic substrate and the coating [23]. The polymer has the ability to oxidize the metallic substrate ensuring the presence of the passive film [24]. Then, the conductive state of the polymer is a fundamental requirement. Moreover, it has been informed that the presence of an anionic surfactant has positive effect on the conductivity of PPy $[25,26]$. The electrical conductivity of all the coatings was determined and their values are shown in Table 4 in order to evaluate and compare them. The higher conductivity corresponds to the BiPPy-pH8 coating which also shows the more compact structure. This result is consistent with the anticorrosive performance obtained for this coating.

It can be stated that the considerable increase in corrosion resistance obtained by bilayers coatings is associated with the combination of the characteristics of each individual layer. This outstanding anticorrosive performance can be attributed to the combination of the following factors: i) the presence of molybdate in the matrix of the inner layer, which not only acts as dopant but also as a corrosion inhibitor, and ii) the presence of AOT as an immobilized dopant in the outer layer due to its large size. Besides the improvement in the barrier properties should be considered. The growth of PPy-AOT film on the PPy- $\mathrm{MoO}_{4}{ }^{2-} \mathrm{NO}_{3}{ }^{-} \mathrm{pH} 8$ coating reduces the film porosity and hence the water mobility through the pores, resulting in better protection for longer periods with respect to single PPy films, inverted bilayers and BiPPy-pH12. As the immersion time increases, the water up taking process begins to be noticeable. This event implies that the amount of electrolyte solution held by coating increases causing a larger surface area to be exposed to corrosion. No surface defects were observed for the BiPPy-pH8 coatings after removing the electrode at the end of the measurements, indicating that the bilayers have a low porosity. Moreover it should also be considered that the corrosion products could provide protection by covering the surface and sealing the open pores.

Table 4. Electrical conductivity values obtained for: $\mathrm{PPy}-\mathrm{MoO}_{4}{ }^{2-} \mathrm{NO}_{3}{ }^{-} \mathrm{pH} 8, \mathrm{PPy}-$ $\mathrm{MoO}_{4}{ }^{2-} \mathrm{NO}_{3}{ }^{-} \mathrm{pH} 12, \mathrm{PPy}-\mathrm{AOT}, \mathrm{BiPPy}-\mathrm{pH} 12, \mathrm{BiPPy}-\mathrm{pH} 8$ and inverted BiPPy.

\begin{tabular}{|l|c|}
\hline Sample & Conductivity $\left(\boldsymbol{\Omega}^{-1} \mathbf{c m}^{-1}\right)$ \\
\hline PPy-MoO ${ }_{4}^{2-}-\mathrm{pH} 12$ & $3.56 \times 10^{-4}$ \\
\hline PPy-MoO ${ }_{4}^{2-}-\mathrm{pH} 8$ & $3.85 \times 10^{-4}$ \\
\hline PPy-AOT & $8.47 \times 10^{-4}$ \\
\hline BiPPy-pH12 & $1.18 \times 10^{-3}$ \\
\hline BiPPy-pH8 & $4.23 \times 10^{-3}$ \\
\hline inverted BiPPy & $5.84 \times 10^{-4}$ \\
\hline
\end{tabular}

\section{Conclusions}

Adherent and compact PPy bilayers films were obtained by a potentiostatic technique on SAE 4140 steel. The corrosion performance of bilayers is superior to that of single PPy films. The improvement in the anticorrosive properties is associated with the combination of characteristics of the single PPy films. These characteristics include the presence of the molybdate which acts as an inhibitor in the inner layer and the role of AOT as immobilized dopant in the outer layer. The 
growth of PPy-AOT film on top of $\mathrm{PPy}-\mathrm{MoO}_{4}{ }^{2-} \mathrm{NO}_{3}{ }^{-} \mathrm{pH} 8$ coating reduces the inner film porosity and hence the water mobility through the pores. PPy bilayers provide protection against the SAE 4140 steel corrosion by both anodic protection and a barrier effect. BiPPy-pH 8 coating was the most effective for corrosion prevention of SAE 4140 steel.

\section{Acknowledgement}

CONICET, ANPCYT and Universidad Nacional del Sur, Bahía Blanca, Argentina are acknowledged for financial support.

\section{References}

1. Grgur BN, Krstaji NV, Vojnovi MV, et al. Prog Org Coat. 1998;33:1-6.

2. Paliwoda-Porebska G, Stratmann M, Rohwerder M, et al. Corros Sci. 2005;47:3216-3233.

3. Herrasti P, Recio FJ, Ocon P, et al. Prog Org Coat. 2005;54:285-291.

4. Koene L, Hamer WJ, de Wit JHW. J Appl Electrochem. 2006;36:545-556.

5. Hosseini MG, Sabouri M, Shahrabi T. Prog Org Coat. 2007;60:178-185.

6. Zhang T, Zeng CL. Electrochim Acta. 2005;50:4721-4727.

7. Kowalski D, Ueda M, Ohtsuka T. Corros Sci. 2007;49:1635-1644.

8. Kowalski D, Ueda M, Ohtsuka T. Corros Sci. 2007;49:3442-3452.

9. Hien NTL, Garcia B, Pailleret A, et al. Electrochim Acta. 2005;50:17471755.

10. Tan C, Blackwood DJ. Corros Sci. 2003;45:545-557.

11. Hasanov R, Bilgic S. Prog Org Coat. 2009;64:435-445.

12. Tüken T, Arslan G,Yazici B, et al. Corros Sci. 2004;46:2743-2754.

13. Lehr IL, Saidman SB. Mater Chem Phys. 2006;100: 262-267.

14. Lehr IL, Saidman SB. Corros Sci. 2007;49:2210-2225.

15. Flamini DO, Saidman SB. Electrochim Acta. 2010;55:3727-3733.

16. Gonzalez MB, Saidman SB. J Colloid Interf Sci. 2007;306:323-327.

18. Ocón P, Cristobal A, Herrasti P, et al. Corros Sci. 2005;47:649-662.

19. Fenelon A, Breslin C. Surf Coat Tech. 2005;190:264-270.

20. Tüken T, Tansug G, Yazici B, et al. Surf Coat Tech. 2007;202:146-154.

21. Olad A, Barati M, Shirmohammadi H. Prog Org Coat. 2011;72:599-604.

22. Lehr IL, Saidman SB. Prog Org Coat. 2013;76:1586-1593.

23. Biallozor S, Kupniewska A. Synth Met. 2005;155:443-449.

24. Hermas AA. Corros Sci 2008;50:2498-2505.

25. Stejskal J, Omastová M, Fedorova S, et al. Polymer. 2003;44:1353-1358.

26. Kudoh Y. Synth Met. 1996;79:17-22. 